\title{
Predicting Infant Outcome in Families of Employed and Nonemployed Mothers
}

\author{
Marsha Weinraub \\ Elizabeth Jaeger \\ Temple University \\ Lois Hoffman \\ University of Michigan
}

\begin{abstract}
Differences in infant outcome, predictor variables, and their relationships were explored as a function of maternal employment. Thirty 18-month-olds and their mothers were studied. Child intelligence, attachment security, and dependency were measured, as well as frequency of stressful events in the mother's life, quality of the parents' marital relationship, frequency of the mother's social contacts, and extent of the mother's emotional and parenting supports. Also included were the mother's ability to cope; satisfaction with emotional, parenting, and child care supports; and role satisfaction. For children of employed mothers, attachment and dependency were negatively correlated; securely attached children showed less dependency behavior. For employed mothers, satisfaction with child care and frequent social contacts predicted secure child attachment. Satisfaction with child care, role satisfaction, and ability to cope were strongly interrelated. For nonemployed mothers, maternal coping predicted attachment security, while frequent social contacts predicted greater child dependency. Predictors of child outcome were highly interrelated for nonemployed mothers, with satisfaction with emotional supports playing a pivotal role. These differences suggest that different models to predict infant outcome in employed and nonemployed mother families may be appropriate.
\end{abstract}

This research was originally presented at the meetings of the Society for Research in Child Development, April 1987, in Baltimore, Maryland. The research was partially supported by grants from the Temple University Biomedical Research Support Fund. The authors are grateful to Susan Ansul, Rose DiBiase, Maureen O'Brien, Loretta Newell, Beverly Coulson, Shirley Landis, and Robert Gress for assistance in all aspects of this research. The comments of Nora Newcombe, the editors, and the reviewers were helpful in revising the manuscript. This study could not have been done without the cooperation and support of the families who participated in the project.

Correspondence and requests for reprints should be addressed to Marsha Weinraub, Department of Psychology, Philadelphia, PA 19122. 
In exploring the effects of maternal employment on infant outcome, researchers have moved beyond looking at differences in children's behavior and developmental outcomes as a function of maternal employment. They have begun to examine the process by which mothers' employment might influence child outcome (Belsky, 1984; Bronfenbrenner \& Crouter, 1982; DeMeis, Hock \& McBride, 1986; Gottfried \& Gottfried, 1988; Hock, 1980; Hoffman, 1974, 1984; Lerner and Galambos, 1986). Some researchers have looked at maternal employment as moderating the levels of other variables in the system, while other researchers have considered maternal employment as a factor that might be influenced by other variables in the system that predicts infant outcome. For example, in his process model, Belsky (1984) has included maternal employment as a variable that might affect as well as be affected by maternal personality and that might influence parenting behavior, with consequences for infant outcome. Owen and Cox (1988) found that mothers who were employed for long hours were more anxious when their infants were three months of age. This anxiety, in turn, was related to the mother's behavior with her infant and the subsequent security of the child's attachment to the mother at one year of age. These researchers recognize, of course, that relationships between maternal employment and other variables in the system might be bidirectional and interactive.

However, researchers are increasingly beginning to see that understanding the effects of maternal employment requires a more specialized view of family processes. Such a view calls for different variables predictive of infant outcome. More important, maternal employment is now being viewed as a situation that dynamically alters the relationships among family variables.

Rather than conceive of maternal employment as a singular variable that might be associated with differences in life stress, marital adjustment, social supports, parenting behavior, and subsequent child outcome, we wondered whether the family processes influencing the infant's outcome might be different in families with employed and nonemployed mothers. Yes, the variables in the system might be the same-life stress, marital adjustment, social supports-but the interrleationships among these variables might be dramatically different in the two types of families. For families with employed mothers, we hypothesized that different variables might be more influential than for the families of nonemployed mothers and that the pattern of interrelationships among critical variables influencing parent-child interactions and infant outcome might be different. Such an approach would affect the generalizations researchers could draw from studies of traditional families with nonemployed mothers to the increasing number of families with employed mothers in the United States today.

In this study, we address three sets of questions that might affect how the effects of maternal employment are conceptualized. The first set of ques- 
tions concerns mean differences. Are there differences in infant outcorne and important predictor variables between families with employed mothers and those with nonemployed mothers? We examined three measures of infant outcome-cognitive development, security of attachment, and dependency-and two levels of predictor variables. On the first level were external influences on the mother that might affect her interactions with her child: the extent of her social contacts, the number of recent life stresses, the quality of her marital relationship, and the extent of parenting and emotional supports. On the second level, we considered more phenomenological variables that might affect the mother's interaction with her child: her sense of her ability to cope with her life situation, her satisfaction with the parenting and emotional supports available to her, her satisfaction with her role as an employed or nonemployed mother, and her satisfaction with child care help. A third level of predictor variables not included in this report would have included direct measures of the mother's interaction with her child.

The second set of questions addressed in this study concerns the relationships between these predictor variables and the child's socioemotional development. How do stress and support variables and phenomenological experiences of the mother influence the child's security of attachment and expressions of dependency behaviors, and are these relationships different in families of employed and nonemployed mothers? A dynamic process model predicts different relationships between the variables in the two types of families.

The third set of questions concerns the system as a whole. Is the pattern of interrelationships among these variables similar in the two types of families? We predicted that since the nonemployed mother's life revolves around issues of home and family, there might be a more integrated pattern of interrelationships among predictor variables than for the employed mothers, whose lives are more affected by divergent factors from the workplace as well as the home. To the extent that the pattern of relationships is similar, generalizations from studies of families with nonemployed mothers to families with cmployed mothers would be supported. Should these patterns be different, we may need to view the processes of influence in these families in different, more specialized ways. We may also need to conceptualize maternal employment as altering not just the levels of important predictor variables, but their dynamic relationships as well.

\section{METHOD}

\section{Subjects}

Thirty mothers and their 18-month-old infants were assessed. Half of the mothers were employed full time and half were nonemployed. Mothers were considered employed full time if they had been employed continuously 
at least 30 hours per week since their child was 4 months old. In fact, the mothers in this group were employed a mean of 40.4 hours per week (range 35 to $\mathbf{4 7}$ hours), and they returned to full-time employment when their infants were 2.1 months old (range 1 to 4 months). Mothers were considered nonemployed if they had not been employed more than 5 hours per week since their child's birth. These mothers worked outside the home a mean of 2.7 hours per week (range 0 to 5 hours).

Employed and nonemployed mothers' families did not differ on income, parental education, parental age, or child birth order. All of the families were white and middle class, and most of the mothers were college educated. Mean annual income for families with employed mothers was $\$ 62,437$ (range $\$ 33,300$ to $\$ 140,000$ ); for nonemployed mothers' families, $\$ 51,540$ (range $\$ 21,500$ to $\$ 140,000$ ). The mean age of mothers in the sample was 31 years; that of the fathers was 33 years.

Infants ranged in age from 17 to 19 months of age, with a mean age of 18.4 months. Sixty percent of the infants were firstborns, $33 \%$ were second children in the family, and $7 \%$ were third children.

Arrangements for child care in the employed-mother group were varied. Twenty-six percent of the children $(n=4)$ were cared for in their own homes by a related or nonrelated caregiver, and an equal percentage were cared for in the home of another person. Forty-six percent of the children $(n=7)$ were in center care.

\section{Procedure}

As part of a larger study of parent-child interaction, mother-infant pairs were observed on two separate occasions, once in the laboratory and once in their homes. Some of the researchers were responsible for telephone interviewing and scheduling; different researchers were responsible for testing and coding. In this way, data could be collected and coded without awareness of the family's employment history. Mothers were asked to be careful about revealing any employment information during the data collection procedures.

The first visit took place in the laboratory, where several measures were collected. During this visit, the Bayley Scales of Infant Development were administered, and the Q-set procedures were explained. The mother was asked to sort the Q-set items into three piles: characteristic of her infant, not at all characteristic of her infant, and a neutral pile. The purpose of this task was to familiarize her with the items so that she could observe her child at home over the next week before completing the final version of the Q-set. Mothers left the lab with a copy of the Q-set cards and a set of questionnaires to complete for the home visit. These were collected one week later from the mothers in their homes. 


\section{Measures}

Attachment and Dependency. To provide continuous measures of attachment security and dependency, the Attachment Q-Set developed by Waters and Deane (1985) was used. According to the procedures they describe, mothers are given a set of 75 items on cards and asked to sort the items into first three and then into nine subdivided piles ranging from most uncharacteristic to most characteristic of the infant's behavior. Finally, working from the outer piles toward the center, the mother adjusts each pile so that it has a specified number of items. The final sort has a symmetrical, unimodal distribution.

Each item is scored in terms of the pile number into which it has been sorted. These scores are then compared to a set of criterion sorts provided by Waters and Deane, one for attachment security and one for dependency. Subjects' scores on each of the two constructs consist of a correlation coefficient between the subject's score array and that of the set of criterion judges.

To prepare the criterion sorts, Waters and Deane had expert judges describe the "hypothetically most $x$ subject" for the constructs of secure attachment and dependency for 12- and 36-month-old children. Because the attachment security criterion sorts that Waters and Deane obtained were highly similar at the two ages, we considered the use of this measure appropriate for 18-month-olds. Use of the 12-month-old dependency criterion is open to some question, as this score was not correlated over the two ages. According to the criterion sorts, attachment and dependency were considered conceptually orthogonal at 12 months of age, but they were somewhat inversely related $(r=-.36)$ at 36 months of age.

Waters and Deane (1985) report that correlations between mothers' Q-set desriptions and a composite score of two independent observers ranged between .59 and .93 , with a mean correlation of .80 .

Developmental Level. The Bayley Mental Scale of Development (1969) was administered to each child in the mother's presence according to standard procedures by a trained tester blind to the mother's employment status.

Stressful Life Events. Stressful life events were measured using the Life Events Survey (LES) developed by Sarason, Johnson, and Siegal (1978). The LES is a self-report measure that asks subjects, using a 47 -item checklist, to rate separately the desirability and impact of events they have experienced during the past year. Drawn heavily from the Holmes and Rahe (1967) Schedule of Recent Experiences, the items were chosen to represent life changes frequently experienced in the general population. Subjects rate events on a 7-point scale ranging from extremely negative to extremely positive. Only scores from items negatively rated were used in the analyses, 
because Sarason et al. (1978) indicated that the negative life event score was the most useful measure in their research; developmental research has confirmed the utility of the negative life event score (Crnic, Greenberg, Ragozin, Robinson, \& Basham, 1983).

In two studies of test-retest reliability of the LES, Sarason et al. report correlations of .56 and .88 for negative life event scores over 5- to 6-week periods.

Marital Adjustment. The Spanier (1976) Dyadic Adjustment Scale (DAS) was used to assess marital adjustment. It is an easily administered 32-item scale measuring dyadic satisfaction, cohesion, consensus, and affectional expression. Goldberg and Easterbrooks (1984) found that the DAS was more related to infant attachment and parenting characteristics than was a couple discussion task measuring marital harmony. Spanier reports that Cronbach's coefficient alpha measure of reliability was .96 for the total scale.

Social Contacts and Social Supports. These measures were taken from the Social Network Form (SNF), a questionnaire concerning the nature and extent of maternal social supports (Weinraub \& Wolf, 1983). The questionnaire asks respondents to list the three friends and relatives (other than the husband) they see most frequently and then to rate the extent to which these relationships are intimate, supportive, and helpful. Questions involve both ratings and free responses. While many items request information about the three people initially listed, several allow consideration of others.

Seven summary scores were used from the SNF. Total social contacts measured the frequency of monthly social contacts that a mother had with the individuals she saw most frequently. This score included contacts with each person individually, in groups, or by telephone or letter. Total emotional supports measured how frequently the mother confided in and obtained emotional support from each of these people, as well as from parenting groups and other organizations. Total parenting supports measured the extent to which the mother valued the parenting beliefs of the people she saw most frequently and the extent of parental support she received from groups and organizations. Satisfaction with the support she received emotionally, as a parent, and with child care help involved the mother's rating of the adequacy of the support in each area. Ability to cope involved ratings on a 5-point scale for the mother's sense of her ability to cope with her life situation, considering her household responsibilities, child care responsibilities, finances, and emotional well-being.

Alpha coefficients computed to determine the internal consistency of individual items making up the summary scores in each area ranged from .65 to .95 , indicating acceptable cohesiveness of items. Test-retest reliability of items on the SNF ranged from .67 to .98 , with a median of .89 . 
Role Satisfaction. On a separate questionnaire, mothers were also asked to rate overall satisfaction with their present role as either an employed or a nonemployed mother using a 5-point scale ranging from unsatisfactory to excellent.

\section{Data Analysis}

To test differences between maternal employment groups on child outcome measures of child developmental level, attachment security, and dependency, analyses of variance with maternal employment status and child sex as factors were used. Tests for homogeneity of variance revealed only one difference between the groups: there was more variability in the amount of parental support that mothers reported in the employed mother group than in the nonemployed group. Pearson Product Moment Correlation Coefficients were used to examine the relationships within each group between child attachment security and dependency. Correlations were examined for boys and girls together in each group, since there were few mean differences and no reason to predict differential relationships. To test differences between the employed and nonemployed groups in the magnitude of these correlations, $z$ tests for differences between correlations were used. Correlations rather than regression analyses were used to assess the relationships among the maternal and child variables, because of the small number of subjects in each group $(n=15)$.

All significant correlations are indicated for the employed-mother group in Figure 1 and for the nonemployed group in Figure 2. All tests were twotailed, and all findings are significant at the .05 level. Where noted, trends $(p<.10)$ are reported for comparison onily.

Because this study was exploratory, many relationships among variables were examined. Examining the correlations among 12 variables for two groups of families exceeds the overall alpha level of .05. Also, the limited number of subjects restricts the power of the analyses. These limitations call for caution in interpreting the results.

\section{RESULTS}

\section{First Set of Questions}

Are there differences in child outcome and in important mediating variables between families with employed mothers and nonemployed mothers?

Child Outcome. No group differences were observed in children's mental development, security of attachment, or dependency scores. Mean Bayley Mental Development scores for children of employed mothers were 113.9; for children of nonemployed mothers, 115.7. Mean attachment security scores for children of both employed and nonemployed mothers were .36 . 


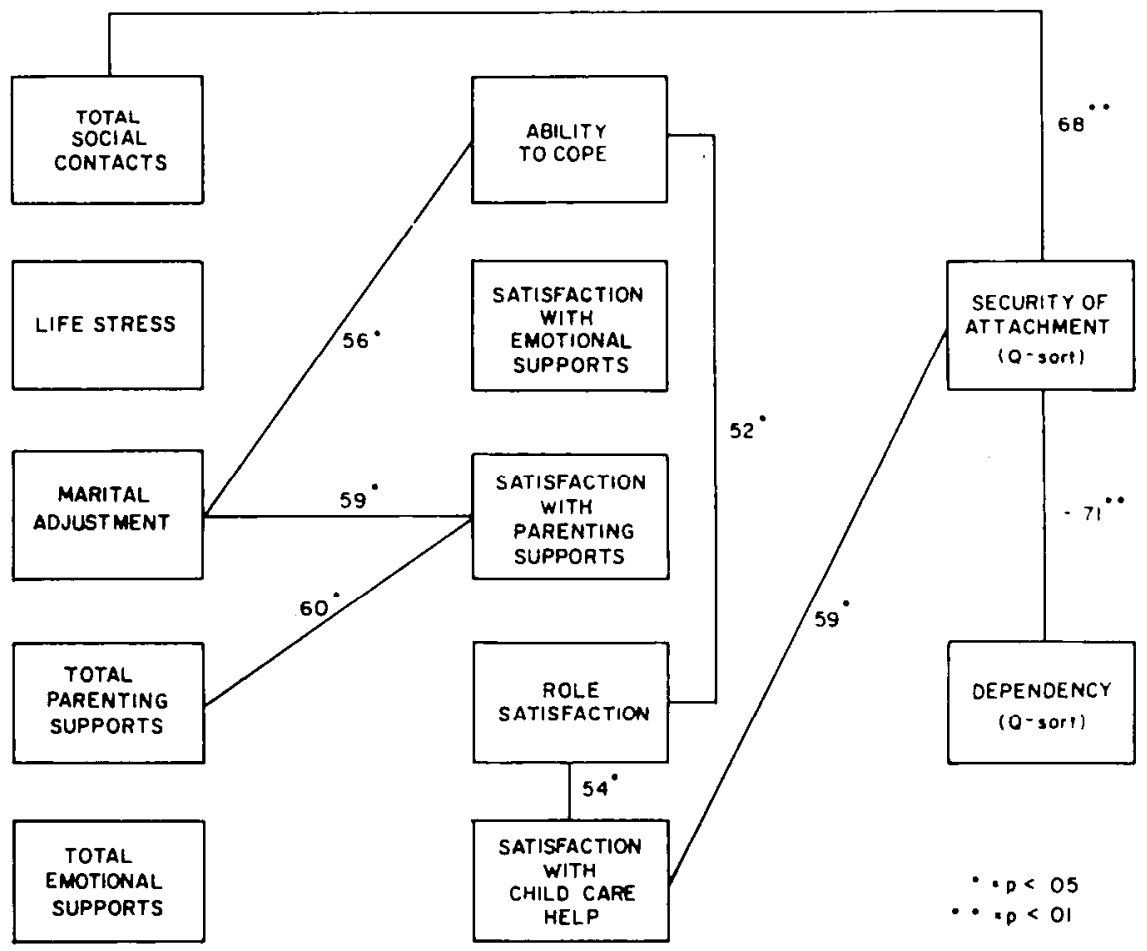

Figure 1. Significant correlations among infant and maternal variables for the employed group $(n=15)$.

Mean dependency scores for children of employed mothers were - .07; for children of nonemployed mothers, .00 .

However, correlations between attachment and dependency scores were different for the two groups. When employed mothers reported that their children showed behaviors characteristic of securely attached children, they rarely included behaviors characteristic of dependent children. The correlation between these children's attachment security and dependency scores was $-.71, p<.01$ (see Figure 1). When nonemployed mothers described their children, security of attachment and dependency behaviors tended to be weakly associated in a positive direction, $r=.42, p<.10$. These correlations are significantly different, $z=3.27, p<.001$. Taken together, they suggest that, for employed mothers and their children, attachment security and dependency behaviors are antithetical, while for nonemployed mothers, child attachment and dependency may be quite compatible.

Predictor Variables. Only one difference was observed between employed and nonemployed mother groups. Employed mothers reported receiving less support in their role as parents than did nonemployed mothers, 


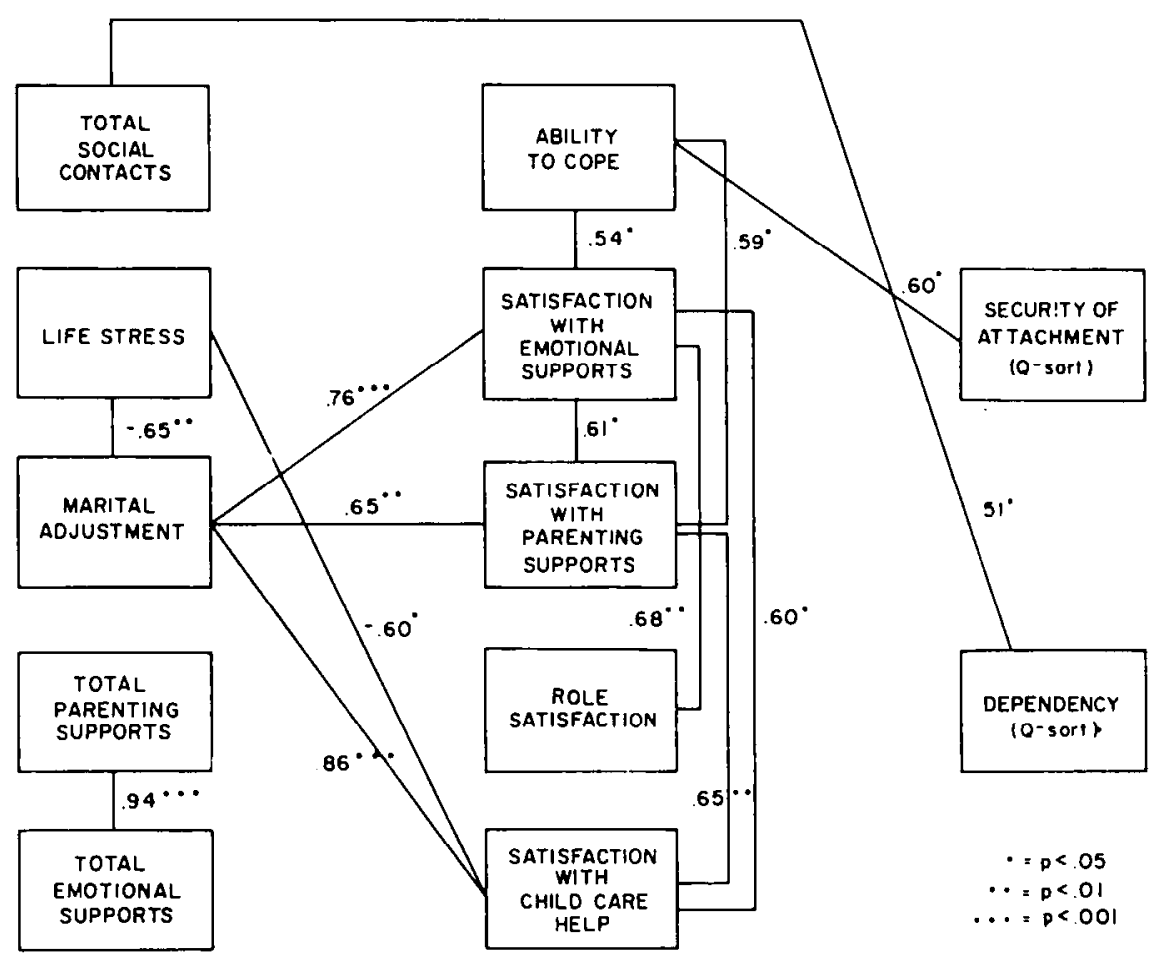

Figure 2. Significant correlations among infant and maternal variables for the nonemployed group $(n=15)$.

$F(1,26)=5.52, p<.02$. There was also a trend for employed mothers to report less satisfaction with their parenting supports, $F(1,26)=3.01, p<.10$.

\section{Second Set of Questions}

How do stress and support variables and phenomenological experiences of the mother affect child outcome? Figures 1 and 2 present graphically the correlations discussed below.

Security of Attachment. For employed mothers, two of the 12 variables predicted security of attachment: satisfaction with child care help, $r=.59$, $p<.05$; and total social contacts, $r=.68, p<.01$. For nonemployed mothers, only the mother's sense of her ability to cope predicted her child's attachment, $r=.60, p<.05$.

Dependency. For employed mothers, none of the variables predicted the child's dependency. For nonemployed mothers, child dependency was related to the frequency of maternal social contacts, $r=.51, p<.05$. More frequent social contacts were associated with mothers' reports of more de- 
pendent behavior in their children. The trend was that the more satisfied the mother with her emotional supports, the more dependent she reported the child $(r=.50, p<.057)$.

\section{Third Set of Questions}

Is the pattern of interrelationships among the predictor variables similar for employed and nonemployed mothers' families?

For employed mothers, the five phenomenological variables were not highly intercorrelated. There were only two relationships: role satisfaction was correlated with the mother's perception of her ability to cope, $r=.52$, $p<.05$; and with her satisfaction with child care help, $r=.54, p<.61, p<.05$. The nature of these relationships, it can be argued, is likely to be reciprocal. The more the mother feels she can cope with her life situation, the more satisfied she is with her role, and vice versa. Likewise, she can be satisfied with her role only if she feels comfortable with the care her child receives in her absence. At the same time, the more satisfied she is with her role, the more comfortable she is with the child care.

For nonemployed mothers, ability to cope and satisfaction with emotional supports, parenting supports, and child care help were all highly intercorrelated. Ability to cope was correlated with satisfaction with both emotional supports, $r=.54, p<.05$; and parenting supports, $r=.59, p<.05$. Satisfaction with emotional supports and satisfaction with parenting supports were also highly related, $r=.61, p<.05$. Although these two similar sounding variables-satisfaction with emotional supports and satisfaction with parenting supports-were highly correlated for the nonemployed mothers, it is interesting that they were orthogonal for the employed mothers, $r=.11$, N.S.

For nonemployed mothers, satisfaction with emotional supports seems to play a pivotal role in the system. This variable was highly related to role satisfaction, $r=.68 p<.01$. It was also highly related to each of the other phenomenological variables-ability to cope, satisfaction with parenting supports, and satisfaction with child care help, $r=.60, p<.05$. Satisfaction with child care help, satisfaction with parenting supports, and satisfaction with emotional supports were also interrelated, but emotional support satisfaction was the only variable that tended to affect child outcome, $r=.50$, $p<.057$. The positive direction of the relationships suggests that the child's dependency may be as much a contributor of emotional support to the mother as it is an outcome of the mother's emotional support.

Interestingly, for employed mothers there were no relationships among the external variables, but two of these influenced the mother's phenomenological state. Perhaps most important is the mother's marital adjustment, which was related both to her ability to cope, $r=.56, p<.05$; and to her satisfaction with her parenting supports, $r=.59, p<.05$. There is a clear and not unexpected relationship between the total number of parenting supports 
available to the employed mother and her satisfaction with them, $r=.60$, $p<.05$. This was not the case, however, with the nonemployed mother, who had significantly more parenting supports available.

For nonemployed mothers, two relationships among the external variables were highly significant. Frequency of stressful life events was negatively related to marital adjustment, $r=-.65, p<.01$; and total parenting and total emotional supports appeared almost identical, $r=.94, p<.001$. In addition, four relationships between the external variables and maternal phenomenological state were highly significant. Life stress was related to the mother's satisfaction with child care help, $r=.60, p<.05$; while marital adjustment was strongly related to satisfaction with emotional supports, $r=.76, p<.01$; with parenting supports, $r=.65, p<.01$; and with child care help, $r=.86, p<.001$. The correlation between marital adjustment and satisfaction with child care help may be strongly influenced by the fact that, for many nonemployed mothers, the husband is the mother's most frequent source of child care help.

\section{DISCUSSION}

The findings suggest the following tentative answers to the three initial sets of questions.

\section{First Set of Questions}

Are there differences in child outcome and important predictor variables between families with employed mothers and nonemployed mothers? Compared with nonemployed mothers, employed mothers reported less support in their role as parents. Since employed mothers also tended to be less satisfied than nonemployed mothers with their parenting supports, this may be an area of potential value for intervention.

More important, no differences were observed in child outcome as a function of maternal employment. Eighteen-month-old children of employed and nonemployed mothers did not differ in developmental level, attachment security, or dependence. This lack of congruence with other reports of differences (see Belsky, 1988) could be explained by a number of factors. In the report that has been frequently cited as indicating adverse effects on attachment security as a function of maternal employment, Barglow, Vaughn, and Molitor (1987) observed children at the age of 12 months. Our children were seen at 18 months; earlier differences in attachment security that might have existed even in our sample at 12 months of age may have washed out. Of course, our measure of attachment security is also different from that used by other researchers. Most have observed children in the Strange Situation, a laboratory technique correlated to subsequent developmental outcome. 
The measure we used, the Attachment Q-Set, is based on maternal report of child behavior in the home as well as in unfamiliar places. Although the two attachment measures may be correlated (Waters \& Deane, 1985), they may tap different kinds of behaviors. On the negative side, maternal report may be disproportionately inflated in the two groups along the lines of social desirability. Additionally, although mothers have been demonstrated to be highly reliable observers, they may not be sufficiently sensitive to pick up the subtle differences that other researchers have been able to identify as differentiating behavior in children of employed and nonemployed mothers. On the positive side, however, this measure offers a wider sample of behaviors and is less likely than the Strange Situation to confound familiarity of setting with employment status.

Another difference between this study and those reported by Barglow et al. (1987) and Belsky and Rovine (1988) was the nature of substitute care received by the children in their mothers' absence. In these two studies, which reported increased incidence of insecure attachment in children of employed mothers, there was little or no center care. Although it is sometimes assumed that in-home care is preferable to center care, many differences between these alternatives (Clarke-Stewart \& Gruber, 1984) could be responsible for discrepancies across studies.

The small size of our sample may not have permitted us the power to find small or moderate differences that might nevertheless exist between children of employed and nonemployed mothers on these measures. One could argue that in investigations that may have important social policy implications, only large differences between groups should be considered, while moderate and small effects are of greater importance for testing issues of theoretical import. The statistical power of our study was .69, which Cohen (1977) considered acceptable for detecting large differences (accounting for at least $14 \%$ of the variance) that might exist between the groups. Our inability to find differences in intelligence and dependency scores in a group of 30 children suggests that any differences that may exist on these measures are not very large. The fact that attachment scores were exactly the same makes it highly unlikely that even small differences exist between the two groups on this measure. Researchers should be sensitive not only to the significance and validity of the findings, but also to the magnitude of the differences that are observed.

It is interesting that, for children of employed mothers, attachment and dependency were negatively related, while, for children of nonemployed mothers, these two measures tended to be positively related. The negative pattern of relationship may indicate a more mature pattern of development for the employed mothers' children, since Waters and Deane (1985) reported that these two measures were orthogonal for 12-month-olds but negative for 36-month-olds. Alternatively, the finding could reflect different rearing 
patterns in the two family types, guided by very different values and family dynamics.

A review of some of the items from the Q-set might be helpful here. The top five scoring items on the attachment security scale are "actively solicits comfort from adult when distressed," "predominant mood is happy," "easily comforted by adult," "affective sharing occurs during play," and "proximity-exploration-proximity cycles are evident in half to one hour observations." Scoring highest on the dependency scale are the items "is demanding when initiating activities with adult," "cries in response to separation," "bouts of exploration and play away from the adult are brief," "is demanding and impatient," and "is upset by negative evaluations or disapproval from adult."

One can see that, whereas the behaviors high on attachment security may be desirable in the families of both employed and nonemployed mothers, the behaviors high on dependency may be differentially valued. Given an already securely attached child, employed mothers may view dependency behaviors as highly undesirable and may discourage them. Nonemployed mothers, on the other hand, may be more likely to tolerate these behaviors, along with behaviors indicative of secure attachment. They may find dependency behaviors not only acceptable, but may even see them as redeeming and self-validating of their choice of employment status. Nonemployed mothers, faced with attached children who also show some of these highly dependent behaviors, may wonder how employed mothers could ever leave their children on a regular basis.

These differences in adaptive behaviors across the two family types are congruent with Hock's research (Hock, Morgan, \& Hock, 1985) showing that the nonemployed mother, even from the time of her child's birth, is more apprehensive about nonmaternal care and more likely than other mothers to believe that infant distress at separation is due to her absence. Although nonemployed mothers are no more likely to have children who score high on attachment or dependency behavior, they might be more likely to tolerate and possibly even welcome or encourage behaviors that promote dependency along with behaviors that indicate attachment. In families with an employed mother, however, dependency behaviors may be selectively screened out of the repertoire of securely attached, well-socialized children.

\section{Second Set of Questions}

How do stress and support variables, phenomenological experiences of the mother, and qualities of substitute care affect child outcome? Different variables predicted child outcome in the children of employed and nonemployed mothers. For employed mothers, greater satisfaction with child care and more social contacts were associated with more securely attached children. For nonemployed mothers, the mother's sense of her ability to cope was 
most predictive of attachment. This suggests that, for nonemployed mothers, issues of personality and personal sense of coping may be critically important in influencing child outcome, as others have suggested (Belsky, 1984), but for employed mothers, availability of satisfactory child care is a critical issue.

While more social contacts predicted greater attachment security in employed-mother families, more social contacts predicted greater dependency in nonemployed-mother families. This differential relationship may reflect differences in the nature of the social support systems of the two sets of mothers or differences in the ways that the mothers used these support systems. Further exploration into the nature of these social contacts is necessary.

\section{Third Set of Questions}

Is the pattern of interrelationships among the predictor variables similar for employed and nonemployed mothers' families? The two patterns here have been found to be quite different. For employed mothers, life stresses, marital adjustment, and parenting and emotional supports are not at all interrelated, while they are strongly related for nonemployed mothers. For nonemployed mothers, stressful life events have a negative effect on marital adjustment, which then affects other variables; parenting and emotional supports appear to be interchangeable. It is as if the system of external influences for nonemployed mothers is highly interdependent, while these same influences in the employed mother's life are more independent and compartmentalized.

For both employed and nonemployed mothers, marital adjustment has an important influence on other parts of the system. The nature of these influences is different, however. Employed mothers with well adjusted marriages are more likely to report greater satisfaction with their parenting supports, perhaps because their husbands are an important source of these supports, and they feel more able to cope with their life situation. In turn, the employed mother is more satisfied with her role as an employed mother. For the nonemployed mother, marital adjustment has stronger and more diverse effects. Marital adjustment is a major influence on the mother's satisfaction with her emotional, parenting, and child care help. Playing a pivotal role in the entire system is the mother's satisfaction with her emotional supports, once again suggesting that for the nonemployed mother, though not necessarily for the employed mother, issues of maternal personality and personal satisfaction within the home are central.

Although much has been said about the importance of the mother's satisfaction with her role, whether employed or not (Lerner \& Galambos, 1986), these data suggest that role satisfaction may have different correlates for the two sets of families and may be of different significance in the family system. For the employed mother, how well she is coping with her life situations and how satisfied she is with child care are major determinants of whether or not she feels satisfied with her role as an employed mother. Remember- 
ing that marital adjustment is the major influence on ability to cope, one wonders whether role satisfaction for the employed mother should not be seen as a by-product of the mother's perception of her skills in balancing the two major relationships in her life-with her husband and with her child. For nonemployed mothers, role satisfaction appears to be a by-product of other important variables in the system, most notably the mother's satisfaction with the emotional supports in her life. Satisfaction with emotional supports plays the key role for these mothers in mediating the influences of marriage and child.

\section{CONCLUSIONS AND IMPLICATIONS}

Our results fail to confirm differences found by Barglow et al. (1987) and Belsky and Rovine (1988), indicating that children of mothers who return to employment in the first year of life are at any greater risk than other children. Indeed, our results are consistent with other studies, such as the one by Chase-Lansdale and Owen (1988), that do not find differences in motherchild attachment security as a function of maternal employment.

Our finding that attachment security and dependency are differentially correlated in children of employed and nonemployed mothers does raise questions about the differential meaning of these measures of child outcome. Employed mothers' children who are reported to show behaviors indicative of secure attachment are usually reported to be quite low on dependent behaviors, while nonemployed mothers' children who are reported to show secure attachment behaviors may or may not demonstrate dependent behaviors. Thus it is not surprising that, in another analysis of data from this sample, employed mothers had sons who showed much less separation distress than nonemployed mothers' sons (Ansul, DiBiase, \& Weinraub, 1987).

These data also cause us to wonder about the validity of attachment measures based on avoidant behavior on reunion in the Strange Situation. In children of nonemployed mothers, failure to greet the mother on reunion may indeed be unusual and may indicate a problem for subsequent development. For employed mothers' children, however, avoidant behavior may not be at all unusual; the child may be used to separations and playing away from the mother.

Although a large and growing literature indicates that avoidant behavior on reunion is a valid measure of attachment and a useful predictor of subsequent attachment-related problems, this literature is predominantly based on children of nonemployed mothers. Indeed, there is some reason to believe that, for children of employed mothers, this measure is less than predictive. For example, Vaughn, Deane, and Waters (1985) found attachment security ratings for children of nonemployed mothers to be predictive of later developmental outcome, while attachment ratings for children of employed mothers were not. Further research is needed to explore the possibility that 
the avoidant behavior commonly believed to indicate insecure attachment may only be predictive of insecure attachments for children of nonemployed mothers. For children of employed mothers, avoidant behaviors may be evidence of adaptive coping mechanisms supported by the demands of the family and of the environment and may not necessarily be predictive of later difficulties.

These data also suggest that different variables in the family system are predictive of optimal socioemotional outcome for children of employed and children of nonemployed mothers. For employed mothers, satisfaction with child care help is a significant predictor of child attachment security. The mother's satisfaction with child care help is strongly related to her role satisfaction, which in turn is affected by the mother's sense of her ability to cope. For families with nonemployed mothers, the mother's sense of her ability to cope is directly related to child attachment. The coping ability of these mothers is related to satisfaction with emotional and parenting supports, which in turn are affected by marital adjustment.

These differential relationships suggest that the types of supports offered to these two different types of families may need to be very different. Employed mothers' families may require better and more accessible substitute child care and day care providers who are sensitive to the employed mother's need for greater support in her role as a parent. In contrast, nonemployed mothers' families may find opportunities to increase the mother's satisfaction with her emotional supports, particularly her marriage, most useful in influencing optimal child outcome.

Finally, these data suggest that the pattern of interrelationships among the predictor variables in the family system may be very different for the two types of families. Families with nonemployed mothers have a much more interdependent pattern of interrelationships among the mediating variables than do families of employed mothers, whose lives migh be affected by variables from the workplace as well as from the home. Because the processes of influence in these families appear to involve different variables with different patterns of interrelationship, we may need to conceptualize maternal employment as altering not just the levels of important predictor variables, which may sometimes occur, but their dynamic relationships as well. We may no longer be able to include maternal employment as one variable in the larger system of family processes that affects child outcome. Instead, we may need to develop different models of influence to explain family processes affecting child outcome in these families.

\section{REFERENCES}

Ansul, S., DiBiase, R., \& Weinraub, M. (1987). Sex differences and separation distress: Effects of maternal employment. Poster presented at the meetings of the Society for Research in Child Development, Baltimore. 
Barglow, P., Vaughn, B.E., \& Molitor, N. (1987). Effects of maternal absence due 10 employment on the quality of infant-mother attachment on a low risk saniple. Child Development, 58, 945-954.

Bayley, N. (1969). Manual for the Behatvioral Scales of Infant Development. New York: Psychological Corporation.

Belsky, J. (1984). The determinants of parenting. Child Development, 55, 83-96.

Belsky, I. (1988). The "Effect" of infant day care reconsidered. Early Childhood Research Quarterly, 3, 227-234.

Belsky, J., \& Rovine, M. (1988). Mother care, other care in the first year of life and the security of infant-parent attachment. Child Development, 59, 157-167.

Bronfenbrenner, U., \& Crouter, A. (1982). Work and family through time and space. In S.G. Kamerman \& C.C. Hayes (Eds.), Families that work: Children in a changing world (pp. 39-84). Washington, DC: National Academy Press.

Chase-Lansdale, L., \& Owen, M.T. (1988). Maternal employment in a family context: Effects on infant-mother and infant-father attachment. Child Development, 58, 1505-1512.

Clarke-Stewart, A., \& Gruber, C. (1984). Day carc: A new context for rescarch and development. In M. Perlmutter (Ed.), Parent-child interaction and parent-child relations in child development. The Minnesota Symposia on Child Psychology (Vol. 17), pp. 61-100. Hillsdale, NJ: Erlbaum.

Cohen, J. (1977). Statistical power analyses for the behavioral sciences (rev. ed.). New York: Academic Press.

Crnic, K.A., Greenberg, M.T., \& Ragozin, A.S. (1984). Maternal stress and social support: Effects on the mother-infant relationship from birth to eighteen months. American Journal of Orthopsychiatry, 54, 224-235.

Crnic, K.A., Greenberg, M.T., Ragozin, A.S., Robinson, N.M., \& Bashman, R.B. (1983). Effects of stress and social support on mothers and premature and full-term infants. Child Development, 54, 209-217.

DeMeis, D.K., Hock, E., \& McBride, S.L. (1986). The balance of employment and motherhood: Longitudinal study of mothers' feelings about separation from their firstborn infants. Developinental Psychology, 22, 627-632.

Goldberg, W., \& Easterbrooks, A. (1984). The role of marital quality in toddler development. Developmental Psychology, 20, 504-514.

Gottfried, A.K., \& Gott lried, A.W. (1988). Maternal employment and children's development: Longindinal research. New York: Plenum.

Hock, E. (1980). Working and nonworking mothers and their infants: A comparative study of maternal caregiving characteristics and infant social behavior. Merrill-Palmer Quarterly, 26, 79-101.

Hock, E. (1984). The transition to day care: Effects of maternal separation anxiety on infant adjustment. In R. Ainslie (Ed.), The child in the day care setting: Qualitative variations and development. New York: Praeger.

Hock, E., Morgan, K.C., \& Hock, M. (1985). Employment decisions made by mothers of infants. Psychology of Women Quarterly, 9, 383-402.

Hoffman, L.W. (1974). Effects of mother employment on the child: A review of the research. Developmental Psychology, 10, 204-228.

Hoffman, L.W. (1984). Maternal employment and the child. In M. Perlmutter (Ed.), Parentchild interaction and parent-child relations in child development. Hillsdale, NJ: Erlbaum.

Holmes, T.H., \& Rahe, R.H. (1967). The social readjustment rating scale. Journal of Psychosomatic Research, 11, 213-218.

Lerner, J., \& Galambos, N.L. (1986). Child development and family change: The influences of maternal employment on infants and toddlers. In L.P. Lipsitt \& C. Rovee-Coltier (Eds.), Advances in Infancy Research (Vol, 4). Norwood, NJ: Ablex. 
Owen, M.T., \& Cox, M.J. (1988). Maternal employment and the transition to parenthood, In A.E. Golltried \& A.W. Golltried, (Eds.), Maternal employment and children's development: Longinudinal research. New York: Plenum.

Sarason, 1.G., Jolunson, J.H., \& Siegal, J.M. (1978). Assessing the impact of life changes: Development of the life experiences survey. Journal of Consulting and Clinical Psychology, 46, 932-946.

Spanier, G.B. (1976). Measuring dyadic adjustment: New scales for assessing the quality of marriage and similar dyads. Journal of Marriage and the Family, 38, 18-28.

Vaughn, B.E., Deane, K.E., \& Waters, E. (1985). The impact of out-of-home carc on childmother attachment quality: Another look at some enduring questions. In I. Bretherton \& E. Waters (Eds.), Growing points in attachment theory and research. Monographs of the Society for Research in Child Development, 50(1-2, Serial No. 209).

Waters, E., \& Deane, K. (1985). Defining and assessing individual differences in attachment relationships: Q-methodology and the organization of behavior and early childhood. In I. Bretherton \& E. Waters (Eds.), Growing points in attachment theory and research. Monographs of the Society for Research in Child Development, 50(1-2, Serial No. 209).

Weinraub, M., \& Wolf, B. (1983). Effects of stress and social supports on mother-child interaction in single and two parent families. Child Development, 54, 1297-1311. 